\title{
The use vacuum therapy in wound healing after fasciotomy in compartment syndrome - case report and literature review
}

\author{
Maria K. Blonska-Staniec, Anna E. Barczak, Anna Garus, Norbert Balchanowski, \\ Jaroslaw P. Miszczuk
}

Vascular Surgery Clinic, Voivodeship Polyclinic Hospital in Kielce, Poland

\begin{abstract}
Fasciotomy (opening of the fascial compartments) is one of the main and most effective methods used for emergency treatment of compartment syndrome. Post-fasciotomy wounds may be the cause of the patient's prolonging hospitalization and may be a challenge in terms of their treatment. In order to avoid potential complications, the wound should be closed as quickly as possible - once the compartment's pressure on the muscle has been relieved. A large size of the surgical wounds constitutes a significant care problem as it may substantially prolong their healing period and increase infection risk. The use of skin transplants may lead to complications and rigid scars both in the place of harvest and the post-fasciotomy wound; therefore immediate wound closure to allow healing by primary intention is a better option for the patient. This technique allows limiting complications and gives better aesthetic effects; however, it may often be difficult to apply due to the significant limb swelling and shrinking or necrosis of the wound edges. In this paper the authors present a case of a 58-year-old man after the open fasciotomy for whom Negative Pressure Wound Therapy (NPWT) was applied as a method auxiliary to compartment syndrome treatment and shortening wound healing period. In the summary, the use of NPWT in facilitating the treatment of compartment syndrome and healing of fasciotomy wound was discussed briefly, based on the literature review.
\end{abstract}

Key words: fasciotomy, lower limb ischaemia, NPWT, compartment syndrome, VAC dressing

Acta Angiol 2016; 22, 4: 158-163

\section{Introduction}

Compartment syndrome is related to the increase of pressure in closed fascial compartments, which significantly limits or even blocks tissue perfusion and causes ischemia, degeneration and necrosis of muscles and nerves. Increase in pressure inside the fascial compartment presses post-capillary veins, causing increase in venous pressure and decrease in arteriovenous gradient, which results in decreased organ perfusion. A significant pressure increase may also cause a direct compression on arterioles causing an increase in resistance of blood flow. An increase in pressure inside the compartment is caused by an increase in volume inside the fascial compartment or by external pressure.

In general, the causes of compartment syndrome may be divided into vascular and non-vascular. The first group includes: reperfusion injury after acute limb ischemia, injuries of arterial and venous system, painful blue oedema and bleeding into fascial compartments. Non-vascular causes include: bone fracture, crush trauma, and iatrogenic causes - immobilizing a limb in a too tight plaster cast, extravasation of large volume of liquid into the compartment (e.g. contrast medium escaping the vascular system) [I]. 


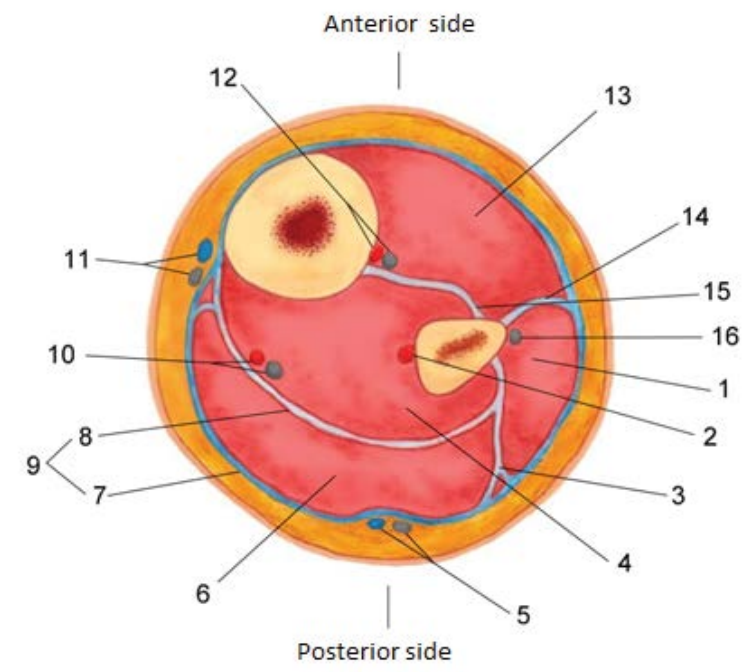

Figure I. Lower leg anatomy — cross section of the right lower leg, view from the top. I) lateral compartment, 2) fibular artery, 3) posterior intermuscular septum, 4) deep posterior compartment, 5) short saphenous vein and sural nerve, 6) superficial posterior compartment, 7) superficial lamina of crural fascia, 8) deep lamina of crural fascia 9) crural fascia, 10) posterior tibial artery, tibial nerve, II) long saphenous vein and saphenous nerve, I2) anterior tibia artery, deep fibular nerve, I3) anterior compartment, 14) anterior intermuscular septum, 15) interosseous membrane, 16) superficial fibular nerve [own drawing]

Late diagnosis and late application of treatment in case of compartment syndrome or lack of treatment often leads to disabilities. Progressing necrosis of muscles and nerves causes local neurological disorders like paralyses and paraesthesia. Muscle strength reduction and contracture often occur.

Often also systemic symptoms are observed like kidney damage, caused by rhabdomyolysis and secondary myoglobinuria, cardiac arrhythmia resulting from a high level of potassium, septicaemia, and in the worst case scenario - a patient's death $[2,3]$.

Compartment syndrome is treated surgically by cutting the fascia (fasciotomy), which allows the pressure in the compartment to come back to normal, which improves microcirculation and thus prevents tissue necrosis [4-6].

Fasciotomy is a surgical procedure which can be performed as open fasciotomy and semi-open fasciotomy. In a semi-open method the fascia is cut through small skin openings. During an open fasciotomy a vast section of skin and the fascia of the tibia is made (Fig. I).

Closure of fasciotomy wounds proceeds gradually. Often it is a multi-phase process and the final closing of the exposed "bare" muscles is done with skin grafts [7]. A long-term exposure of tissue, increasing infection risk, significantly enhanced the patient's hospitalization time, increasing the costs of treatment [8].

Nowadays more and more often the Vacuum Assisted Closure (VAC) therapy, allowing the faster closure of the wound after fasciotomy. The beneficial influence of the NPWT in wound management has been known for a long time. The earliest reports on application of the negative pressure therapy in treating of infected wounds of human patients date in the 80 s of the $20^{\text {th }}$ century. In 1995 the NWWT was officially approved by the Food and Drug Administration in the USA as a treatment method to be applied in acute or chronic trauma wounds. In 2000 these recommendations were extended to include transplant wounds and in 2002 - burn wounds [9].

In spite of the fact that the NPWT is commonly used in the clinical practice, we are still learning new possibilities of application for this method. The VAC dressings are successfully applied in general surgery, plastic surgery, paediatric surgery, vascular surgery, traumatology, cardio surgery, dermatology and urology.

The authors of this paper would like to share their experience in applying the NPWT in fasciotomy wound management in compartment syndrome treatment.

\section{Case study}

A 58-year-old man was originally admitted to the Vascular Surgery Clinic, District Polyclinic Hospital in Kielce in April 2015 due to acute ischaemia of the right lower limb. The CT examination showed occlusion of the superficial femoral artery (Fig. 2).

At that time the femoral-popliteal bypass surgery was performed with the use of a Dacron graft $(6 \mathrm{~mm}$ diameter), distal anastomosis above the knee. The ankle-brachial index of the right lower limb on the day of hospital discharge was 0.77 .

In USG Doppler the bypass was patent; also no symptoms of thrombosis or abnormal fluid retention points were visible. The patient was admitted to hospital for the second time in April 2016 with acute ischaemia of the 


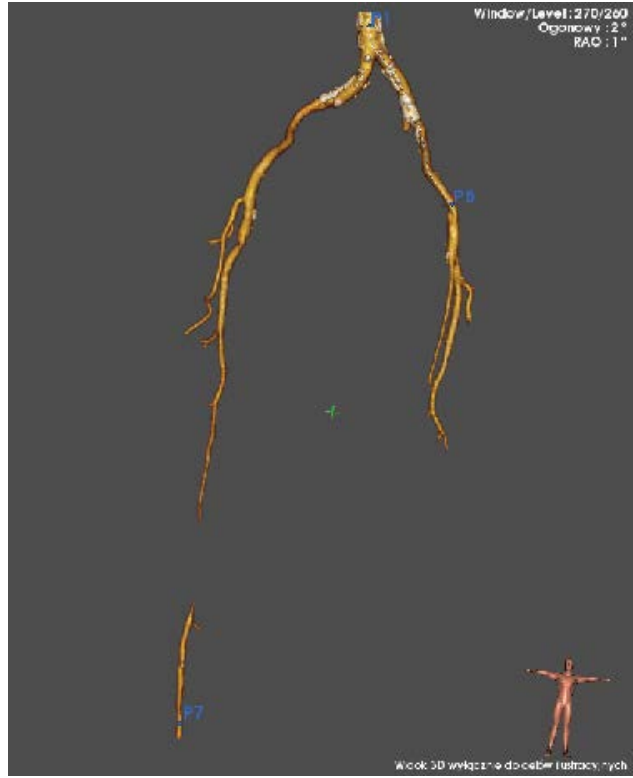

Figure 2. Angio CT reconstruction - ischaemia of the right lower limb

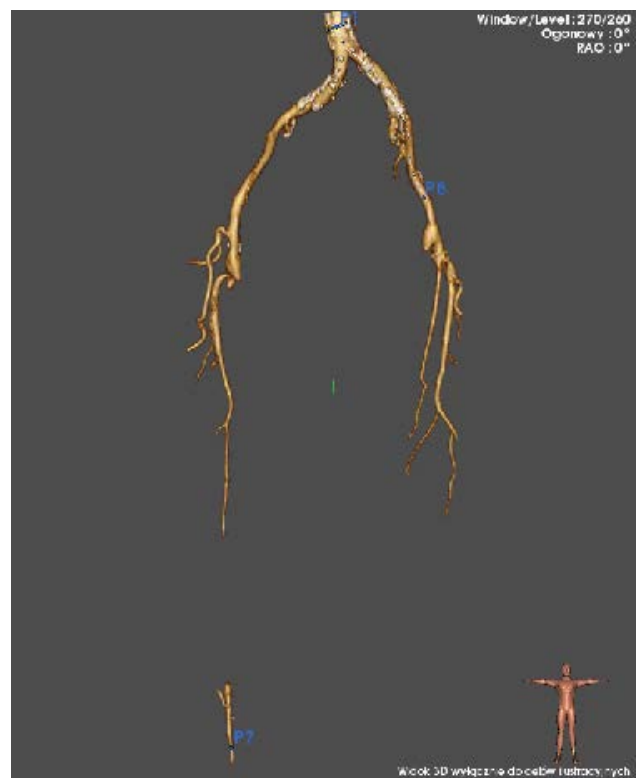

Figure 3. Angio CT reconstruction - the femoral-popliteal bypass thrombosis on the right side

right lower limb caused by the femoral-popliteal bypass thrombosis confirmed in CT scans (Fig. 3).

After the unsuccessful attempt of thrombolytic treatment, an emergency thrombectomy with a balloon plasty of the right popliteal artery and the occlusion in the distal bypass anastomosis was performed. Initially, the outcome of the surgery was satisfactory. On the next day the blood circulation in the limb worsened. The patient was re-operated - the bypass anastomosis was revised and removed, and a short bypass to the end of the popliteal artery stent was done.

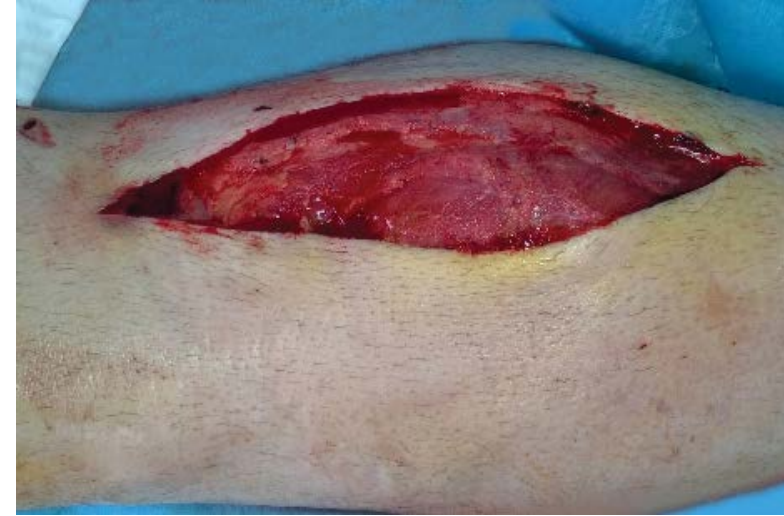

Figure 4. Open fasciotomy of the lower leg, medial cut - superficial and deep posterior compartment
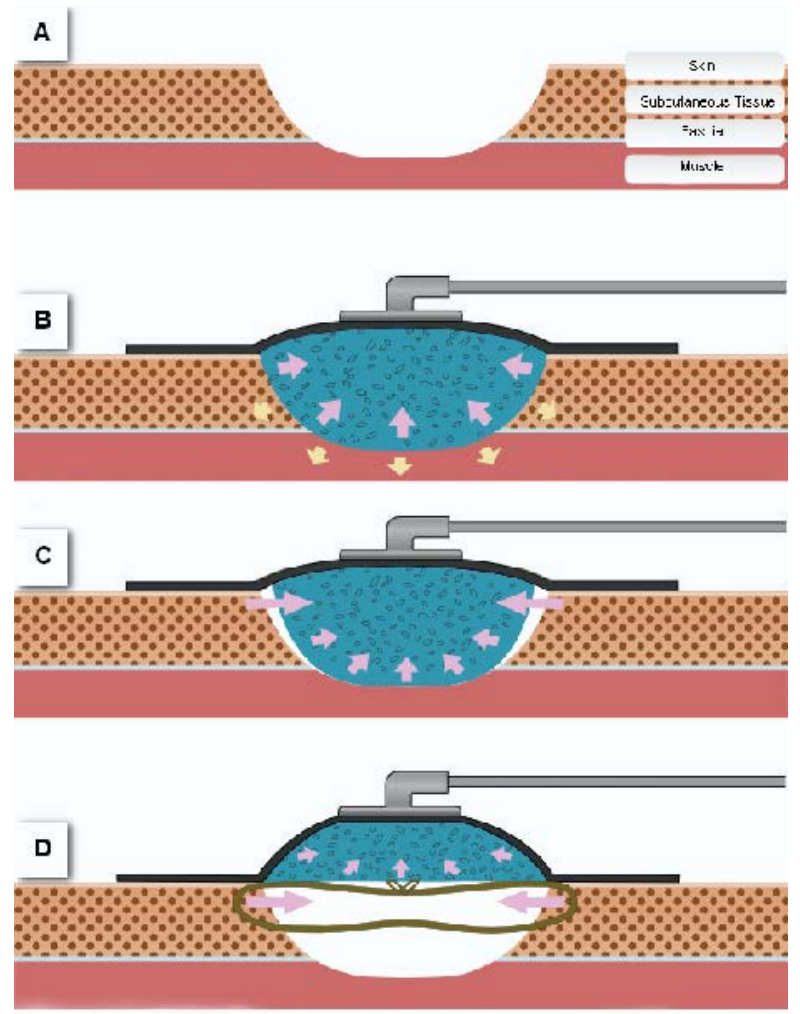

Figure 5. Application of the NPWT with "ideally" fitted size of the sponge causes the stretching of the wound edges (A, B). Application of the NPWT with a smaller sponge in relation to the wound size and delayed primary closure with sutures facilitates primary closure and thus significantly shortening the time to definite closure (C, D) [own drawing]

The pulse on the popliteal artery below the anastomosis was restored. On the next day after the surgery oedema, increased tension of the right tibia was observed and the patient complained about very strong pain. The compartment syndrome was diagnosed. An open four-compartment fasciotomy was performed and the blood circulation in the limb improved (Fig. 4). 


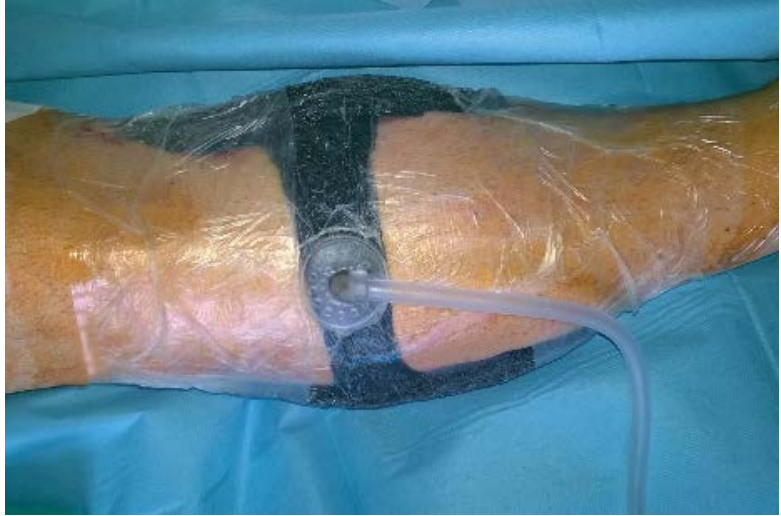

Figure 6. Application of NPWT on both fasciotomy wounds (day I after the surgery). The dressing with the bridge. Connecting both wounds with fluid collector located in the middle of the bridge. $1000 \mathrm{~mL}$ of fluids was drained

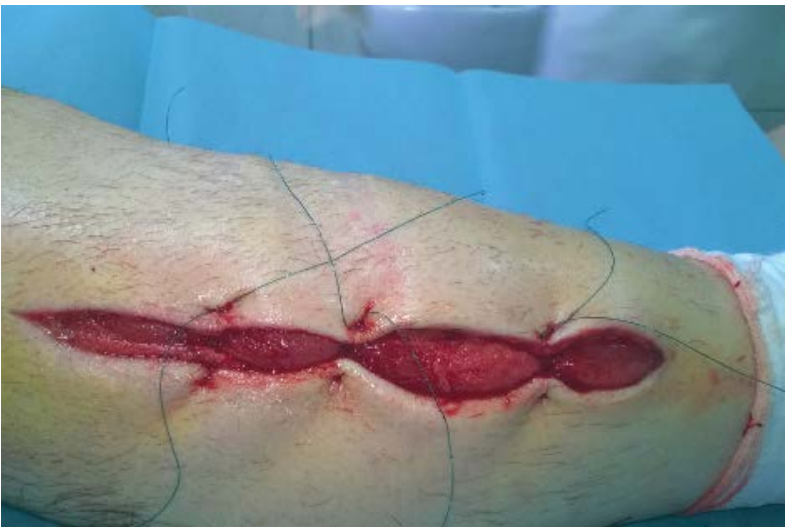

Figure 7. Second change of dressing using the NPWT (day 4 after the surgery). Delayed primary closure with sutures - lateral cut

In the first day after fasciotomy, the NPWT was applied in order to reduce oedema, evacuate excess of fluids and reduce infection risk. During the dressing application, a smaller size of sponge in relation to the wound was chosen - with the assumption that this will not stretch the wound, which will have beneficial effect on primary closure process during the next dressing replacement (Fig. 5).

During the first day after the surgery the negative pressure of $80 \mathrm{~mm} \mathrm{Hg}$ was applied (Fig. 6). On subsequent days the pressure was increased to $120 \mathrm{~mm} \mathrm{Hg}$ and maintained at this level until the therapy was finalized. The dressing was changed on $1^{\text {st }}, 4^{\text {th }}$ and $7^{\text {th }}$ day after the surgery (Fig. 7). On II th day the NPWT was finished and local wound treatment was started with the use of specialist dressing.

The wound condition being satisfactory and blood circulation in the limb restored, the patient was discharged from the hospital on $14^{\text {th }}$ day of hospitalization ( $12^{\text {th }}$ day after fasciotomy) in good general condition, with recommendation to appear for the follow-up treatment in the vascular surgery clinic. For the wound man-

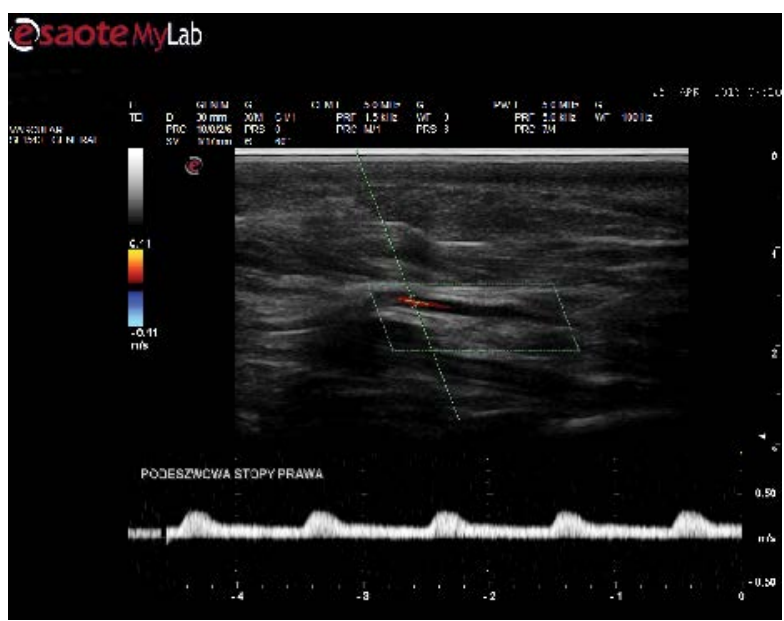

Figure 8. Blood flow through the right foot plantar artery

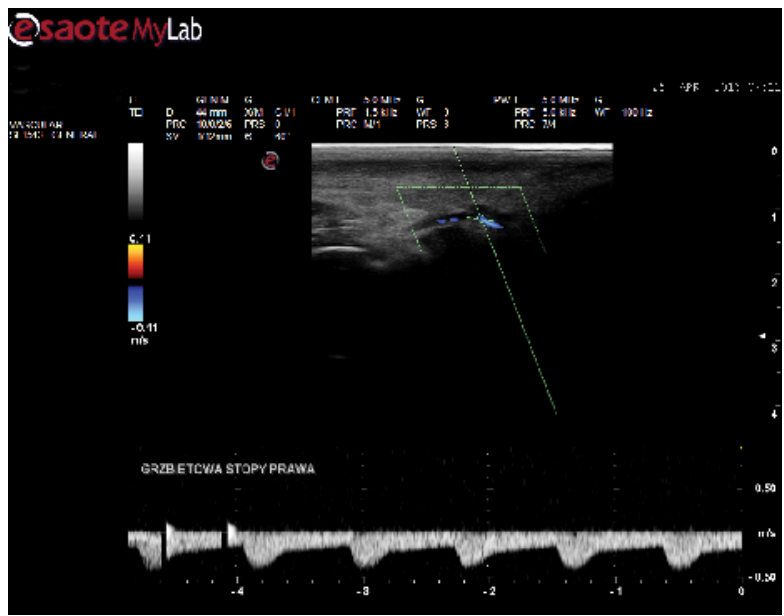

Figure 9. Blood flow through the right foot dorsal artery

agement specialist wound dressing with ionic silver and foam dressing with hydrogel layer were recommended.

During the first follow-up visit (day $19^{\text {th }}$ after fasciotomy) the correct wound healing was observed. Further application of specialist dressings was recommended. The Doppler images showed the blood flow through the right foot arteries (plantar and dorsal arteries as well as and collateral circulation in the posterior tibial artery) (Fig. 8, 9). The patient did not complain about pain.

The follow-up examination of the fasciotomy wounds on $23^{\text {rd }}$ day after the surgery revealed further progress of the wound healing process. Further application of specialist dressings was recommended. USG images showed the blood flow through the right popliteal artery. The bypass was patent without any features of thrombosis or abnormal fluid retention. The pulse in the foot detected. The $A B I$ on the right side was 0.98 .

The progress of the wound healing allowed for extending the time periods between the follow-up visits in the clinic. On $33^{\text {rd }}$ day after the surgery application of traditional dry aseptic dressings was recommended. 


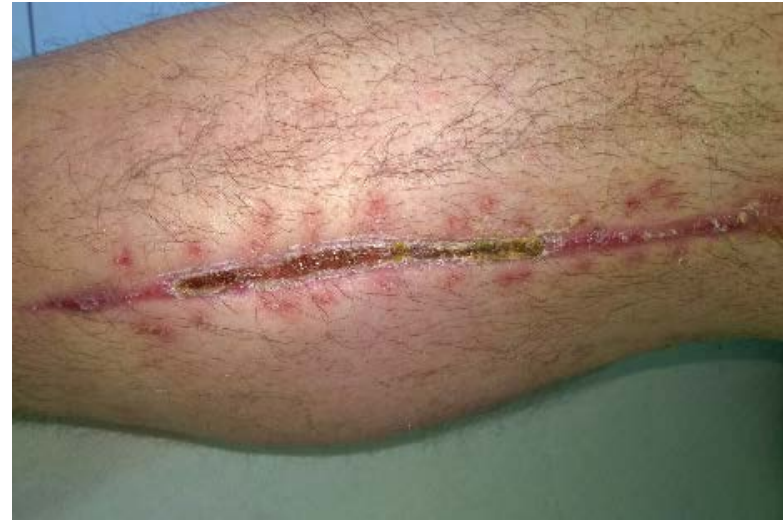

Figure 10. Post-surgery wound on 49 day after fasciotomy - medial cut

The definite closure of the wound was observed on $49^{\text {th }}$ after the surgery (Fig. 10).

\section{Discussion}

The negative pressure wound therapy of the surgical wound has beneficial effects on many factors of healing process - it reduces oedema and possibility of wound dehiscence by reducing the tension and skin retraction of the wound edges near the sutures; it also reduces risk of wound infection as well as haematoma and fluid retention.

Additionally the NPWT improves microcirculation, stimulates granulation tissue formation and permits faster ingrowth into the wound filler, which results in shortening of hospitalization time [ $10, \mathrm{I} \mathrm{I}]$. Additionally, the VAC application gives better aesthetic effects [12]. The literature review support the use of the NPWT in fasciotomy wound management in the course of compartment syndrome treatment.

The study conducted by Yang et al., which compared the results of treatment of fasciotomy wounds with the use of the NPWT therapy and delayed primary closure with sutures or skin graft coverage of the wounds (no NPWT), showed much shorter time to definite closure in the group of patients for whom the VAC was applied. A matched series of 34 consecutive antecedent patients after the standard two-incision release of all four compartments, with the same entry criteria, except for the use of the VAC, were also studied and served as a control group. Of the 68 wounds, in 34 patients managed with VAC, the average time to definitive closure for both the lateral and the medial wounds was 6.7 days. For the 70 wounds in the 34 control patients, the average time to definitive closure was 16 .I days [II].

In this retrospective chart review conducted by Zannis et al., which included a consecutive series of patients over a 10-year period, the analysed series included 458 patients who underwent 804 fasciotomies. The objective was to examine differences in fasciotomy wound outcomes, comparing the vacuum-assisted closure (VAC) device, traditional wet-to-dry dressings, and combination thereof. Of these fasciotomy wounds, 438 received exclusively VAC dressings, 270 received only normal saline wet-to-dry dressings, and 96 were treated with a combination of both. In comparing all wounds, there was a statistically significant higher rate of primary closure using the VAC versus traditional wet-to-dry dressings. The time to primary closure of wounds was shorter in the VAC. group in comparison with the non-VAC group. It has been shown that the VAC used in treatment of fasciotomy wounds decreases hospitalization time, allows for earlier rehabilitation, and ultimately leads to increased patient satisfaction [13].

Weiland, using the example of three patients with compartment syndrome, described the benefits resulting from the use of the VAC and HBOT to close the fasciotomy wounds [14].

The retrospective chart review conducted by Saziye Karaca et al. compared the VAC treatment with the conservative treatment of the fasciotomy wound until definitive surgical closure. All the fasciotomies were performed on the patients suffering from ischaemia reperfusion syndrome. It was shown that due to the beneficial influence on the wound healing process VAC device can be a new standard for treatment of fasciotomy wounds [10].

In Poland VAC method in fasciotomy wound treatment is certainly used in many specialist clinics; however, the authors of this paper have not found any publications on results of this method in the Polish journals.

\section{Conclusions}

The VAC therapy used in treatment of fasciotomy wounds reduces wound oedema, enables faster primary closure of wounds and granulation tissue, thus substantially decreasing hospitalization time.

\section{References}

I. Modrall JG (2010) Trauma and Acute Limb Ischemia: Compartment Syndrome. [In]: Cronenwett JL, Wayne Johnston K (ed.) Rutherford's Vascular Surgery. Saunders Company; 24I2-242I.

2. Finkelstein JA, Hunter GA, Hu RW (1996) Lower limb compartment syndrome: course after delayed fasciotomy. J Trauma; 40: 342-344.

3. Williams $A B$, Luchette FA, Papaconstantinou HT et al (1997) The effect of early versus late fasciotomy in the management of extremity trauma. Surgery; 122: 86I-866. 
4. Mullett H., Al-Abed K., Prasad CV et al (200I) Outcome of compartment syndrome following intramedullary nailing of tibial diaphyseal fractures. Injury; 32: 4II-4I3.

5. Lagerstrom CF, Reed RL $2^{\text {nd }}$, Rowlands BJ et al (1989) Early fasciotomy for acute clinically evident posttraumatic compartment syndrome. Am J Surg; 158: 36-39.

6. Olson SA, Glasgow RR (2005) Acute compartment syndrome in lower extremity musculoskeletal trauma. J Am Acad Orthop Surg; 13: 436-44.

7. Jensen SL, Sandermann J (1997) Compartment syndrome and fasciotomy in vascular surgery. A review of 57 cases. Eur J Vasc Endovasc Surg; 13: 48-53.

8. Giannoudis PV, Harwood PJ, Kontakis G et al (2009) Long-term quality of life in trauma patients following the full spectrum of tibial injury (fasciotomy, closed fracture, grade IIIB/IIIC open facture and amputation ). Injury; 40: 213-219.

9. Babiak I, Żakiewicz W, Luterek M et al (20II) Zastosowanie opatrunków podciśnieniowych VAC w kompleksowym leczeniu złamań IIIB i IIIC podudzia z masywnym ubytkiem tkanek miękkich. Chirurgia Narządów Ruchu i Ortopedia Polska; 76: I54-I56.

10. Saziye K, Mustafa C, Ilker U et al (201I) Comparison of vacuum-assisted closure device and conservative treatment for fasciotomy wound healing in ischaemia-reperfusion syndrome: preliminary results. Int Wound j; 8: 229-236.

II. Yang CC, Chang D, Webb LX (2006) Vacuum-assisted closure for fasciotomy wounds following compartment syndrome of the leg. J Surg Orthop Adv; 15: 19-23.

12. Fraccalvieri M (2016) Terapia podciśnieniowa rany chirurgicznej [In]: Walczak D, Banasiewicz T et al (eds). Leczenie metodą otwartego brzucha - kiedy i jak. Termedia; 243-245.

13. Zannis J, Angobaldo J, Marks M et al (2009) Comparison of fasciotomy wound closures using traditional dressing changes and the vacuum-assisted closure device. Ann Plast Surg; 62: 407-409.

14. Weiland DE (2007) Fasciotomy closure using simultaneous vacuum-assisted closure and hyperbaric oxygen. Am Surg; 73: $26 \mathrm{I}-266$. 